\title{
The Effect of Three Consecutive Context Sentences on EFL Vocabulary-Learning
}

\author{
Sasan Baleghizadeh and \\ Mohammad Naseh Nasrollahy Shahry
}

\begin{abstract}
Investigations into the role of context have often failed to find a positive role for this in vocabulary learning. This study, following a line of research concerned with the role of context, adds to the literature by examining the effect of three consecutive context sentences instead of one. Thirty-three Iranian EFL learners were asked to learn 20 challenging English words in two conditions. They encountered half of the words in three consecutive sample sentences plus their Farsi equivalents and the other half merely with their Farsi equivalents devoid of any context sentences. The results of both immediate and delayed post-tests revealed a positive role for context sentences in vocabulary learning. It is proposed that successful vocabulary learning through context sentences could be attributed to the mixed effects of both context and frequency of occurrence.
\end{abstract}

Les études sur le rôle du contexte n'ont pas souvent réussi à trouver une influence positive du contexte dans l'apprentissage du vocabulaire. Cette étude, qui s'inscrit dans une lignée de recherches portant sur le rôle du contexte, contribue à la littérature en examinant l'effet de trois phrases contextuelles consécutives plutôt qu'une seule. Nous avons demandé à 31 Iraniens qui apprenaient l'anglais comme langue étrangère d'apprendre 20 mots anglais difficiles dans deux conditions. La moitié des mots ont été présentés dans trois phrases contextuelles consécutives avec leur équivalent en persan, l'autre moitié uniquement avec leur équivalent en persan, sans contexte. Les résultats des post-tests qui ont immédiatement suivi l'exercice et des post-tests différés ont révélé que les phrases contextuelles jouent un rôle positif dans l'apprentissage du vocabulaire. Nous proposons que l'apprentissage du vocabulaire par les phrases contextuelles réussit grâce à l'effet tant du contexte que de la fréquence de présentation.

\section{Introduction}

In recent years we have witnessed the publication of a substantial number of books devoted to vocabulary-learning research (Bogaards \& Laufer, 2004; Carter \& McCarthy, 1988; Coady \& Huckin, 1997; Lewis, 1993, 1997; Nation, 2001; Singleton, 1999). As Singleton remarked, this reevaluation of the role of vocabulary in second-language acquisition (SLA) is a reflection of a similar shift toward recognition of the great potential of vocabulary in linguistics. 
This reinvented conception of the role of vocabulary is driven by the realization that a great deal of the difficulty experienced by second-language learners relates to lack of vocabulary.

Intuitively, the context in which learners encounter words would seem to play a significant role in their subsequent learning. Surprisingly, relatively few studies have sought to investigate the role of context in learning vocabulary. From the standpoint of depth of vocabulary knowledge, the surroundings of a word carry a great deal of pertinent information. This study is an attempt to uncover the effect of context-operationalized in terms of three consecutive sample sentences in which target vocabulary items appear-on vocabulary learning.

Vocabulary has been studied in two distinct strands of research in SLA, namely, the incidental and intentional modes. In order to locate this article in the framework of vocabulary learning research, these two lines of research are explored in the literature review that follows.

\section{Literature Review}

Hulstijn (2003) set out several interpretations of incidental and intentional learning. The simplest definition, which is also the most common among vocabulary-acquisition researchers, is that incidental vocabulary-learning refers to a setting where learners do not make a deliberate attempt to commit words to memory. Thus any effort to sensitize learners to being tested on a given set of words would constitute a context for intentional vocabulary-learning (see, e.g., Laufer \& Girsai, 2008, for incidental; Webb, 2005, for intentional vocabulary learning).

A commonly held view as to the genesis of incidental vocabulary-learning is that the bulk of vocabulary acquisition occurs through extensive reading (Krashen, 1989). This assumption fails to stand up to close scrutiny. In fact many students fall short of the $98 \%$ text coverage-amounting to knowledge of 8,000-9,000 word families (Nation, 2006) - that is a prerequisite for successful comprehension (Keating, 2008). Investigations pitting the two kinds of vocabulary-learning against each other have revealed that intentional learning in general is more successful than incidental vocabulary-learning (Pressley, Levin, \& McDaniel, 1987). Having learners guess the meaning of words from context has been found an unreliable approach to vocabularylearning in that learners tend not to have a good sense of the accuracy of their guesses (Kaivanpanah \& Alavi, 2008). However, Nation (2001) voiced a view now common among vocabulary researchers when he pointed out that both intentional and incidental vocabulary-learning are commonly employed learners' strategies and that the two are complementary in the sense that learners learn words both by studying specific words and by learning them after encountering them in context. Therefore, this claim, coupled with the testimony of many language-learners and teachers, points to the importance 
of incidental vocabulary-learning as a supplement to overall acquisition of vocabulary.

Thus it is important for a study of the role of context in vocabulary-learning to include a definition of context. A number researchers have attempted to define context in the framework of vocabulary-learning. Engelbart and Theuerkauf (1999) broke context down into two categories: verbal and nonverbal. Accordingly, context has two dimensions, each consisting of a few aspects. Verbal context includes both the grammatical and semantic contexts. Morphological and syntactical clues make up the grammatical context, and word associations such as collocations, synonyms, and antonyms constitute the semantic context. The nonverbal context includes the situative context, which refers to the location, speaker, time, acting person, and matter that surrounds the word; the descriptive context, which refers to the sentence that partly explains the meaning of the unknown word; the subject context, which refers to the information a person already has about a given subject; and the global context, which refers to a person's general knowledge that extends beyond the subject of the material, that is, his or her knowledge of the world.

Vocabulary tasks with no context have proven very effective (Webb, 1962; Griffin, 1992). On the other hand, contextualized tasks like reading texts with new words embedded in them have been found to yield extremely poor results in terms of learning words (Swanborn \& de Glopper, 1999). A few studies have suggested that decontextualized vocabulary tasks work as well as, if not better than, contextualized activities (Laufer \& Shmueli, 1997; Prince, 1996). However, as Webb (2007a) pointed out, it is difficult to draw firm conclusions on the basis of these studies because many of them compare incidental learning from context with intentional learning through a decontextualized task, making it hard to evaluate the effects of context accurately. Seen in another light, in these comparisons the two learning conditions were not on the same footing inasmuch as the learners in the intentional condition had access to the word definitions and would not have to make an extra effort to guess their meanings, whereas the learners in the incidental condition had to guess the meaning of the words without any guarantee that the inferred meaning would be correct. As this suggests, this set of studies allows another factor to enter the picture, namely, the capacity to guess.

Fortunately, however, a number of studies have controlled for these variables. These studies have compared the effect of vocabulary-learning in context with list-learning to shed light on the role of context in isolation from confounding variables. Laufer and Shmueli (1997), for example, set out to compare the relationship between memorization of new words (short-term and long-term) and four modes of vocabulary presentation and diverse languages of vocabulary glossing. The four modes they studied were words presented (a) in isolation; (b) in "minimal context," that is, in one meaningful sentence; (c) in text context; and (d) in "elaborated" text context, that is, in 
the original text supplemented by clarifying phrases and sentences. In each mode of presentation, half of the words were translated into the learners' L1 and half were explained in English. In addition, another group, who were asked to learn the words for a quiz by themselves, served as a control. All learners were tested on their short-term and long-term retention of the given words. The results of the study revealed that L1 glossing was more conducive to learning than L2 glossing and that words presented in lists and sentences were retained better than words presented in either type of texts. Thus it was concluded that mental elaboration may not necessarily emerge when words are presented in texts. This study was one of the first attempts to make a distinction between vocabulary-learning in a minimal context (where the target word appears in a single sample sentence) and in a text context (where the target word appears in a piece of discourse, say, a paragraph).

Another study that investigated the effect of a single-context sentence on vocabulary-learning was Webb (2007a), which compared two groups of learners: one participating in a task involving learning words in glossed sentences, and the other completing a learning word-pairs task. Webb wished to determine if a single-sentence context had an effect on vocabulary-learning. This study was similar in design to Laufer and Shmueli's (1997), the major difference being that he examined vocabulary learning in five dimensions: orthography, meaning and form, syntagmatic associations, paradigmatic associations, and grammatical functions. This study falls into the category of intentional learning in that the learners were informed that after the experiment, they would be tested on the vocabulary items. Not unlike the result of other studies in this line of research, presenting vocabulary in the context of one meaningful sentence did not yield much benefit. There was a modest difference in the various tests, suggesting that diverse types of knowledge are affected to almost the same degree. There was even a trend toward the word-list group outperforming the single-sentence context group, although no statistically significant difference was found. Similarly, other studies designed to compare word-learning in isolation and in context failed to show either to be superior. For example, Griffin (1992) pointed out that contextualized vocabulary tasks might be more effective for intermediate and advanced learners and less so for beginners on the basis of the intuitive belief that certain qualities of vocabulary presented in context might prove helpful for advanced learners who have no difficulty with the other words in the sentences.

In contrast to such studies that show little difference between the two conditions, others have yielded mixed results (Grace, 1998; Prince, 1996; Qian, 1996; Seibert, 1930). As Hulstijn (2003) and Nation (1982) rightly pointed out, the confusion may have arisen because context is a multifaceted construct.

An effective way to break down the challenge facing a language-learner who is learning a vocabulary item is to distinguish between knowing a word 
and using a word $(\mathrm{Gu}, 2003)$. If one is to use a word communicatively, one must know the word and be able to use it in a sentence. In studies of context, it is critical to assess the differential effects of word-list learning and vocabulary-learning in context on both the capacity of learners to use the word and their knowledge of it. It is important to distinguish these two dimensions given that a key aspect of vocabulary-learning in context purports to be of benefit in terms of providing learners with a sample context where the word is used naturally. Such learning might form the basis of the learner's subsequent accurate use of the word in a sentence in a communicative situation. Moreover, a common criticism leveled at word-pair learning has long been its failure to provide learners with the means to use the word. Therefore, in any study of the effects of context, it would be worth investigating how context affects a learner's ability to use the word.

Another point worth noting is that in most of the cited studies, more than one group of learners was assigned to varied conditions (Laufer \& Shmueli, 1997). Although not inherently a design flaw, this type of design with diverse groups does not readily accommodate the possibility that individual differences might play a role. Individual differences in vocabulary-learning strategies have been investigated on several occasions (Boyle, 1987; Sanaoui, 1995). These individual differences aside, the mere fact that diverse learners undertake varied tasks to some extent confounds the individual difference factor with the overall design.

More recently, repetition and frequency have come to the forefront in the field of SLA (Ellis, 2002). These have been perceived as a key variable in determining word retention in vocabulary research (Rott, 1999; Webb, 2007b; Zahar, Cobb, \& Spada, 2001). Webb and Rott found, among others, an accumulative effect of repetition of the unknown word in either a sentence or a text. It is now widely accepted that the more a vocabulary item is encountered, the better are the chances of remembering it. Thus the difference between this study and earlier studies is that the latter were conducted in the context of incidental vocabulary-learning research. It may well be that repetition and frequency of occurrence of vocabulary items could carry over to intentional vocabulary-learning.

\section{The Present Study}

\section{Research Questions}

As the above discussion demonstrates, a few issues in the literature on vocabulary-learning in and out of context warrant further investigation. In particular, three issues stand out in the context of our study.

The number of repetitions of every word has been shown to play a positive role (Rott, 1999; Webb, 2007b). It remains to be seen in view of frequency 
effects in incidental vocabulary-learning whether this frequency effect carries over to intentional vocabulary-learning. To pursue this goal, the learners in this study were provided with three consecutive context sentences.

Methodologically, considering that there is no means of ensuring that two separate groups will fare the same as far as memory is concerned, it would be worthwhile to use one group to undertake both conditions so as to minimize as far as possible the effect of individual differences.

Noteworthy in this context is how the vocabulary knowledge scale (VKS) test (Paribakht \& Wesche, 1997) can potentially add another insightful dimension to this study. The test requires learners to put the given words into sentences after demonstrating their knowledge of the meaning of the words. Of both theoretical and practical interest would be how the two vocabulary learning conditions differentially affect vocabulary knowledge. In particular, the study seeks to examine the extent to which the three consecutive context sentences may affect the ability to compose new sentences in addition to knowledge of the meaning of the words.

In the light of the above discussion, in this study we intended to explore the following research questions.

1. Do learners learn vocabulary items presented in three consecutive context sentences plus their L1 equivalents (Condition 1) better than words simply presented with their L1 equivalents (Condition 2)?

2. Can learners make new sentences with words presented in Condition 1 better than with words presented in Condition 2?

\section{Participants}

The participants in this study were 40 adult students (18 men and 22 women) with an average age of 22 who were studying English as a foreign language in a private language institute in Mashhad, Iran. The participants, mostly university students, were members of three intact classes whose scores on the TOEFL varied from 450 to 560 . The first class consisted of 13 students (4 men and 9 women), the second 13 students ( 6 men and 7 women), and the third 14 students (8 men and 6 women). Questionnaires distributed before the experiment revealed that the participants had been studying English in private language institutes for five years on average. Consultation with their respective teachers and an examination of the books they had studied provided corroborating evidence that the participants would not know the words used in the context sentences.

\section{Pilot Study}

Before the main study, we deemed it appropriate to conduct the experiment with a similar group in terms of their English background to find out how long it would take the participants to follow the instructions and learn the 
20 target words. At the end of this pilot study, the learners reported no serious difficulty with the target words. In addition, it was found that on average they would need a maximum of 10 minutes to learn the words.

\section{Design}

The experiment was conducted in the participants' regular class time and followed a within-subjects design. Therefore, all the participants encountered the same words in the same order under two conditions. Ten words were presented in three consecutive context sentences plus their L1 equivalents in Farsi (Condition 1), and the other 10 words appeared only with their L1 equivalents and no context sentences (Condition 2). The list of words and the context sentences and their Farsi equivalents appear in Appendix A.

The participants were told that they would be tested on the words, but were not told about the nature of the test. For the purpose of this study, a modified version of the vocabulary knowledge scale (VKS) was used. The modified scale, unlike the original with five levels of knowledge, assigns three levels of knowledge and control of a given word. Hence it requires learners to provide a definition either in their L1 or in English, which earns them one point. The next level requires participants to use the given word in an English sentence, which earns them an extra point. So there are three possible scores for every word: 0 if the learner does not know the meaning of the word, 1 if the learner writes the word's meaning, and 2 if the learner makes a correct English sentence with the given word in addition to writing its meaning. The modified VKS contained all the words selected for the experiment, so both the pretest and the post-tests contained all 20 target words.

A potential complication was how to score the sentences on the immediate and delayed post-tests. The second part of the VKS requires learners to compose a sentence with a given word. The difficulty lay in establishing fair criteria for how to score the sentences as most sentences composed by learners are often either semantically or syntactically ill formed. Because composing a sentence following one's first encounter with a word is a demanding task because learning a word is said to be a long-term enterprise (Bogaards \& Laufer, 2004), we decided to mark as correct all sentences that did not contain global grammatical errors and would make sense semantically. This implied that heavily flawed sentences composed by some of the participants would be unscored.

\section{Target Words}

An issue of paramount importance in vocabulary studies is that the words selected be unknown to the participants. To this end, in certain studies, nonsense words are also used. However, considering that in addition to being part of a research project, this study was intended as an educational experience for the learners, we did not adopt this option. Thus to ensure that the 
learners had not encountered the words before the experiment, we examined an issue of the New Yorker to search for a number of difficult words that we assumed would be unfamiliar to the learners. We also checked the selected words with the classroom teachers, who verified that they were beyond the learners' knowledge. A pretest (the VKS) was also administered, which determined that most of the learners did not know the target words.

Another important issue regarding the selection of words is their part of speech. Barcroft (2004), for example, limited the vocabulary in his experiment to concrete nouns, and Folse (2006) restricted his research to verbs. In contrast, Webb $(2007$ a, 2008) used a 6:4 ratio of nouns to verbs so as to be more representative. Following Webb, we decided to stick to the $6: 4$ ratio of nouns to verbs on the assumption that this came closest to their frequency of occurrence in natural texts (Kucera \& Francis, 1967).

\section{Procedure}

Before the experiment, the second researcher informed the participants of the purpose of the study, and all volunteered to take part in the research project. After filling in a questionnaire that mostly asked for the participants' educational background and experience in learning English, they were given the pretest, which revealed that the target words were unknown to most of them. To avoid carry-over of words from the pretest to the treatment, the participants were engaged in their normal classroom activities for 45 minutes. They were then presented with the 20 target words in written form and asked to learn them in no more than 10 minutes. Next they were given the immediate post-test, which they completed in 10 minutes. A week later, we returned to administer the delayed post-test, which resembled the immediate post-test. As mentioned above, the study followed a within-subject design, and the scores on both conditions were related to each other. Therefore, a paired sample $t$-test was used to compare the effects of both conditions.

\section{Results}

Based on the results of the pretest, seven students knew at least one of the target words, so their scores on the post-tests were excluded. As mentioned above, the data were analyzed by using a paired sample t-test because it was a within-subjects comparison and the scores on both learning conditions were related. Tables 1 and 2 show the descriptive statistics for both groups of words, that is, those that appeared in three consecutive context sentences in addition to their L1 equivalents (Condition 1) and those that were presented with merely L1 equivalents (Condition 2) on the first part of both posttests, in which the participants were required to write the meaning of the words. The results of the immediate post-test indicated that the mean score of the participants in Condition 1 was significantly higher than their mean scores in Condition 2: $t(64)=-5.45, p=.001$. The same held true for the delayed 
post-test, that is, the participants' performance on words that had appeared in context sentences plus their L1 equivalents was significantly better than their performance on words paired only with their L1 equivalents: $t(64)=-5.06, p=.001$.

Tables 3 and 4 show the descriptive statistics for both groups of words on the second part of both post-tests. The participants' sentence-making performance in Condition 1 proved to be better than their performance on words that they had encountered apart from context sentences on both immediate and delayed post-tests with a moderate effect size: $t(64)=-5.75$, $p=.001$, and $t(64)=-4.70, p=.001$, respectively.

\section{Discussion}

The answer to both research questions was affirmative. Learners exposed to context sentences did better in terms retaining words, and they were also able to compose more correct sentences with them. However, a word of caution is in order. The learners who were exposed to context sentences had three sentences on which to draw as models, and it is plausible that part of their better sentence-making scores could be accounted for by their exposure to these sentences. Nevertheless, it is worth observing that the study was primarily concerned with the retention rates of the words, and so the fact that

Table 1

Mean Scores, Standard Deviations, and $t$-Value for Both Groups of Words on the Immediate Post-test (Meaning Recognition)

\begin{tabular}{lcccccc}
\hline Groups & $n$ & $M$ & $S D$ & $d f$ & $t$ & sig \\
\hline Condition 1 & 33 & 6.6 & 2.23 & 64 & -5.45 & .001 \\
Condition 2 & 33 & 5.03 & 2.24 & & & \\
\hline
\end{tabular}

p<.05.

Table 2

Mean Scores, Standard Deviations, and $t$-value for Both Groups of Words on the Delayed Post-test (Meaning Recognition)

\begin{tabular}{lllllll}
\hline Groups & $n$ & $M$ & $S D$ & $d f$ & $t$ & sig \\
\hline Condition 1 & 33 & 5.58 & 2.17 & 64 & -5.06 & .001 \\
Condition 2 & 33 & 4.24 & 2.15 & & & \\
\hline
\end{tabular}

$p<.05$. 
Table 3

Mean Scores, Standard Deviations, and $t$-Value for Both Groups of Words on the Immediate Post-test (Sentence-Making)

\begin{tabular}{llccccc}
\hline Groups & $n$ & $M$ & $S D$ & $d f$ & $t$ & $s i g$ \\
\hline Condition & 133 & 11.45 & 4.47 & 64 & -5.75 & .001 \\
Condition & 233 & 7.69 & 4.64 & & & \\
\hline
\end{tabular}

$p<.05$.

Table 4

Mean Scores, Standard Deviations, and $t$-Value for Both Groups of Words on the Delayed Post-test (Sentence-Making)

\begin{tabular}{lllllll}
\hline Groups & $n$ & $M$ & $S D$ & $d f$ & $t$ & sig \\
\hline Condition 1 & 33 & 9.63 & 4.18 & 64 & -4.70 & .001 \\
Condition 2 & 33 & 6.81 & 4.32 & & & \\
\hline
\end{tabular}

$p<.05$.

learners consistently performed better on both delayed post-tests in one condition provides evidence of better retention in the context-sentences condition. This study can be viewed as a follow-up to earlier studies that sought to explore the usefulness of context in vocabulary-learning (Laufer \& Shmueli, 1997; Prince, 1996, Webb, 2007b). In most of the earlier studies, the learners encountered the target words only once either in a single sentence or in a text. This study departs from earlier ones in its use of three consecutive context sentences instead of one. We decided to use three sentences instead of one because of the surge of interest in the effect of frequency backed by empirical evidence in the field of SLA in general (Ellis, 2002) and vocabulary-learning in particular (Folse, 2007). The results of our study seem to indicate that the three context sentences were effective in terms of leaving a more durable imprint on the minds of the learners as reflected in the results.

Frequency seems to have been favorable for vocabulary-learning, as it was in several other studies (Horst, Cobb, \& Meara, 1998; Webb, 2007b). However, it remains unclear whether the superior effect of vocabulary-learning in the consecutive context condition arose from the presence of context and the ensuing elaboration of meaning or the mere frequency of words. We cannot favor one over the other in the light of the present findings, but we venture to suggest that the frequency of the encounter had a significant role 
in the effects observed on the grounds that frequency of repetition is a significant determiner in vocabulary-learning. It seems, therefore, safe to propose that a single context was not sufficient in the earlier studies and that more frequent contexts are required to ensure a positive effect.

An important issue worth examining here is what is meant by knowledge of a word. Haastrup and Henriksen (2000) argued that lexical competence has three dimensions: (a) partial-precise, which they define as referring to diverse levels of comprehension of the same lexical item; (b) receptive-productive, which as the name suggests, relates to whether one's knowledge of a given word is receptive or productive; and (c) depth of knowledge, which is a word's paradigmatic (antonymy, synonymy, hyponymy, etc.) and syntagmatic relations (collocational restrictions). Regarding the partial-precise dimension, both frequency and context are critical factors. Apparently, the first time a word is encountered, it is not the word but a fragment of it that is acquired. Therefore, it takes many encounters to ensure that a word is learned in its precise form. It is well known that using a word productively is more difficult than using it receptively (Webb, 2008). From the perspective of the receptive-productive dimension, again if a word is seen only once, competence does not become productive. It is only when a word has been encountered many times or in several contexts that it can reach the stage of productive knowledge. Depth of knowledge, a frequently neglected area in vocabulary research, cannot be gained on one encounter given the limited input that EFL learners receive. Similarly, it requires many encounters in various contexts to develop a sound knowledge of syntagmatic relations. It is precisely here that context may be believed to have the greatest potential. Learners may be able to memorize a word by repeating it so many times that the form becomes second nature to them, but it is only through facing the challenge of interpreting what a word in a sentence means that learners gain control of how to use a word in terms of collocational restrictions.

\section{Conclusion}

Our findings suggest that frequency and context have an important place in vocabulary-learning. Although learning new words through context-free activities such as working on word pairs might be a powerful tool to enhance one's breadth of vocabulary knowledge, this study provides strong evidence that adding a minimum of three contextually appropriate sentences to L1 glosses results in a significant improvement in vocabulary-learning. Moreover, as attested by the results of the delayed post-test, consecutive-context sentences pave the way for long-term learning.

The study offers a number of practical implications. Pedagogically, it indicates the need to furnish learners with more sample sentences when it comes to presenting vocabulary. This is significant in that earlier research has demonstrated that one sentence including the given word benefits learning 
very little. On the other hand, authors of textbooks seem to have a propensity for presenting isolated words either in designated boxes or in the context of a passage, which essentially provides only one context for the given word. It appears that students would be in a better position to learn and retain new words if they were provided with repeated contexts through exposure to more sample sentences. Given the scanty attention given to sufficient context sentences in textbooks, at present it is up to teachers to supply them to learners.

This study reveals a positive role for context in intentional vocabulary research. However, an important issue needs further exploration. It is still not clear whether the superior performance of the participants with respect to learning the new words in Condition 1 should be attributed to the role of context or of frequency of encounters. In other words, is it the elaborative nature of the context, or is it the frequency of occurrence that promotes better vocabulary learning? Future research is warranted to unravel this issue.

\section{Acknowledgments}

The authors thank the anonymous TESL Canada Journal reviewers for their helpful comments on an earlier draft of this article.

\section{The Authors}

Sasan Baleghizadeh is an assistant professor of TEFL at Shahid Beheshti University, G.C. of Iran, where he teaches applied linguistics, syllabus design, and materials development. He is the author of Tales from Rumi, Tales from Men of Wisdom, and a number of other simplified readers, all published by the Iran Language Institute. His recent publications have appeared in TESL Reporter, ELT Journal, and The Teacher Trainer.

Mohammad Naseh Nasrollahy Shahry is currently a doctoral candidate in TEFL at Shahid Beheshti University, G.C. of Iran. His main research area is teaching vocabulary in EFL contexts.

\section{References}

Barcroft, J. (2004). Effects of sentence writing in second language lexical acquisition. Second Language Research, 20, 303-334.

Bogaards, P., \& Laufer, B. (Eds.). (2004). Vocabulary in a second language: Selection, acquisition, and testing. Amsterdam/Philadelphia, PA: John Benjamins.

Boyle, J.P. (1987). Sex differences in listening vocabulary. Language Learning, 37, 273-284.

Bresnan, J. (1982). The mental representation of grammatical relations. Cambridge, MA: MIT Press.

Carter, R., \& McCarthy, P. (Eds.). (1988). Vocabulary and language teaching. London: Longman.

Carter, R. (1998). Vocabulary: Applied linguistic perspectives. London: Routledge.

Coady, J., \& Huckin, T, (Eds.). (1997). Second language vocabulary acquisition: A

rationale for pedagogy. Cambridge, UK: Cambridge University Press.

Ellis, N.C. (2002). Frequency effects in language acquisition: A review with implications for theories of implicit and explicit language acquisition. Studies in Second Language Acquisition, 24, 143-188.

Engelbart, S.M., \& Theuerkauf, B. (1999). Defining context within vocabulary acquisition. Language Teaching Research, 3, 57-69.

Folse, K.S. (2006). The effects of type of written exercise on L2 vocabulary retention. TESOL Quarterly, 40, 273-293. 
Grace, C.A. (1998). Retention of word meanings inferred from context and sentence- level translations: Implications for the design of beginning-level CALL software. Modern Language Journal, 82, 533-544.

Griffin, G.F. (1992). Aspects of the psychology of second language vocabulary learning. Unpublished doctoral dissertation, University of Warwick, UK.

$\mathrm{Gu}$, P. (2003). Vocabulary learning in a second language: Person, task, context and strategies. TESL-EJ, 7, 2.

Haastrup, K., \& Henriksen, B. (2000). Vocabulary acquisition: Acquiring depth of knowledge through network building. International Journal of Applied Linguistics, 10, 221-240.

Horst, M., Cobb, T., \& Meara, P. (1998). Beyond a clockwork orange: Acquiring second language vocabulary through reading. Reading in a Foreign Language, 11, 207-223.

Hulstijn, J.H. (2001). Intentional and incidental second language vocabulary learning: A reappraisal of elaboration, rehearsal and automaticity. In P. Robinson (Ed.), Cognition and second language instruction (pp. 258-286). Cambridge, UK: Cambridge University Press.

Hulstijn, J.H. (2003). Incidental and intentional learning. In C.J. Doughty \& M. Long (Eds.), Handbook of second language acquisition (pp. 349-381). Oxford, UK: Blackwell.

Keating, G.D. (2008). Task effectiveness and word learning in a second language: The involvement load hypothesis on trial. Language Teaching Research, 12, 365-386.

Kaivanpanah, S., \& Alavi, M. (2008). Deriving unknown word meaning from context: Is it reliable? RELC Journal, 39, 77-95.

Krashen, S. (1989). We acquire vocabulary and spelling by reading: Additional evidence for the input hypothesis. Modern Language Journal, 73, 440-464.

Ku era, H., \& Francis, W.N. (1967). A computational analysis of present-day American English. Providence, RI: Brown University Press.

Laufer, B., \& Girsai, N. (2008). Form-focused instruction in second language vocabulary learning: A case for contrastive analysis and translation. Applied Linguistics, 29, 694-716.

Laufer, B., \& Shmueli, K, (1997). Memorizing new words: Does teaching have anything to do with it? RELC Journal, 28, 89-108.

Lewis, M. (1993). The lexical approach: The state of ELT and a way forward. Hove, UK: Language Teaching.

Lewis, M. (1997). Implementing the lexical approach: Putting theory into practice. Hove, UK: Language Teaching.

Nation, I.S.P. (1982). Beginning to learn foreign vocabulary: A review of the research. RELC Journal, 13, 14-136.

Nation, I.S.P. (2001). Learning vocabulary in another language. Cambridge, UK: Cambridge University Press.

Nation, I.S.P. (2006). How large a vocabulary is needed for reading and listening? Canadian Modern Language Review, 63, 59-82.

Paribakht, T., \& Wesche, M. (1997). Vocabulary enhancement activities and reading for meaning in second language vocabulary acquisition. In J. Coady \& T. Huckin (Eds.), Second language vocabulary acquisition: A rationale for pedagogy (pp. 174-200). Cambridge, UK: Cambridge University Press.

Pressley, M., Levin, J. R., \& McDaniel, M.A. (1987). Remembering versus inferring what a word means: Mnemonic and contextual approaches. In M. McKeown \& M. Curtis (Eds.), The nature of vocabulary acquisition (pp. 107-128). Mahwah. NJ: Erlbaum.

Prince, P. (1996). Second language vocabulary learning: The role of context versus translations as a function of proficiency. Modern Language Journal, 80, 478-493.

Qian, D. (1996). ESL vocabulary acquisition: Contextualization and decontextualization. Canadian Modern Language Review, 53, 120-42.

Rott, S. (1999). The effect of exposure frequency on intermediate language learners' incidental vocabulary acquisition and retention through reading. Studies in Second Language Acquisition, 21, 589-619. 
Sanaoui, R. (1995). Adult learners' approaches to learning vocabulary in second languages. Modern Language Journal, 79, 15-28.

Seibert, L.C. (1930). An experiment on the relative efficiency of studying French vocabulary in associated pairs versus studying French vocabulary in context. Journal of Educational Psychology, 21, 297-314.

Singleton, D. (1999). Exploring the second language mental lexicon. Cambridge, UK: Cambridge University Press.

Swanborn, M.S.L., \& de Glopper, K. (1999). Incidental word learning while reading: A metaanalysis. Review of Educational Research, 69, 261-85.

Webb, S. (2005). Receptive and productive vocabulary learning: The effects of reading and writing on vocabulary knowledge. Studies in Second Language Acquisition, 27, 33-52.

Webb, S. (2007a). Learning word pairs and glossed sentences: The effects of a single context on vocabulary knowledge. Language Teaching Research, 11, 63-81.

Webb, S. (2007b). The effects of repetition on vocabulary knowledge. Applied Linguistics, 28, 46-65.

Webb, S. (2008). The effect of context on incidental vocabulary learning. Reading in a Foreign Language, 20, 232-245.

Webb, W.B. (1962). The effects of prolonged learning on learning. Journal of Verbal Learning and Verbal Behavior, 1, 173-82.

Zahar, R., Cobb, T., \& Spada, N. (2001). Acquiring vocabulary through reading: Effects of frequency and contextual richness. Canadian Modern Language Review, 57, 541-572.

\section{Appendix A}

\section{Target Words with Their Farsi Equivalents and Sample Sentences}

\section{Scourge: مشكل}

International terror has become a scourge of our civilized society

Inflation was the scourge of the fifties.

Life was easier before the scourge of war.

\section{Menage: خانه دارى}

\section{Smattering: مقدار كم و سطحى}

I heard smatterings of laughter.

It's not enough to have a smattering of a language.

He only has a smattering of Portuguese.

\section{Mendacity: كذب ، دروغكويى}

\section{Marshal: حمع كردن}

You have to marshal your arguments before you speak.

He didn't marshal his thoughts. Therefore, he couldn't speak well.

The candidate is trying to marshal support.

\section{Efface: Eحوكردن}




\section{Revamp: روبه راه كردن}

BBC plans to revamp the show before next season.

The room needs to be revamped.

The house has recently been revamped.

\section{Retract: حرف را يس كرفتن}

\section{Rile: عصبانى كردن}

The class riled me up.

Do not let the interviewer rile you.

The decision riled a lot of people in the country.

\section{Souse: در آب قوطه ور كردن}

\section{Luster: حلوه}

There will be a celebrity guest to add luster to the occasion Autumn had given the trees an extra golden luster.

The luster of the celebration was the fireworks.

\section{Melee: غوغا}

\section{كثيفى :}

I was disgusted by the grunge of the room.

What's that grunge there?

The desk was covered with grunge.

\section{Grunt: ناليدن}

\section{Morph: عوض شدن}

The river had morphed into a giant sea.

Computers are morphing into a new thing.

The team had morphed into six teams.

\section{Lynch: كشتن بدون محاكمه}

\section{Innuendo: كنايه}

She found her innuendoes irritating

This campaign is based on innuendo and gossip.

His writing is full of innuendoes. 


\section{Adversity: مشكل}

\section{Scout: حستجو كردن.}

I am scouting for a place to live

The police are scouting for the body of the victim.

She is scouting for a job opportunity.

\section{Scowl: اخم كردن}

